\title{
Dynamic Game-theoretic Model for Coordinating Pricing and Inventory Decisions in a Supply Chain with Retailer Competition
}

\author{
Yun Huang ${ }^{1, a}$, George Q. Huang ${ }^{2, b}$, Kuifun Ip Gang ${ }^{1, \text { a }}$ \\ ${ }^{1}$ Macau University of Science and Technology Taipa, Macau, PR China \\ ${ }^{2}$ Department of Industrial and Manufacturing Systems Engineering, University of Hong Kong, \\ Hong Kong, PR China \\ aemail: yuhuang@must.edu.mo, bemail:kli20112012@163.com
}

\begin{abstract}
Keywords: Supply Chain; Dynamic Non-cooperative Game; Nash Equilibrium; Pricing; Inventory
\end{abstract}
\begin{abstract}
In this paper, we discuss how a manufacturer interacts with his multiple competing retailers to optimize their individual net profits through coordinating pricing and inventory decisions in a two-echelon supply chain. The manufacturer purchases raw materials outside to produce substitutable products to different retailers. The manufacturer determines his optimal wholesale prices for different retailers, setup time interval for the products and replenishment cycle for raw materials to maximize his profit. For each retailer, he considers optimal retail prices and replenishment policies to maximize his profit. The problem is modeled as a dynamic non-cooperative game in which all the competing retailers formulate a subgame and as a sector play the whole game with the manufacturer. Analytical method and solution algorithm are developed to determine the Nash equilibrium of this game. A numerical study is conducted to examine the influence of market and production related parameters on decisions and profits of the supply chain and its constituent members.
\end{abstract}

\section{Introduction}

Inconsistence and incoordination existed between local objectives and the total system objectives make the supply chain lose its competitiveness increasingly [1]. For many industries, the coordination of price decisions with inventory means an approach that improves the efficiency of both the supply chain and individual firms [2].

Coordinating pricing and inventory decisions has been studied by many researchers at about fifty years ago. Whitin [3] shows that the retailer could obtain greater profits when coordinating the price and order quantity decisions. Kunreuther and Richard [4] find the same results for the inter-department coordination in a manufacturer and a retailer. More recently, some researchers have focused on coordination for the seller-buyer supply chains. Weng [5] proposes a model of supplier-retailer relationship and confirm that the coordination of pricing and inventory decisions benefits both supply chain system and individual firms. Different from these literature focused on one wholesaler and one retailer situations, Boyaci and Gallego [6] study pricing and inventory policies that maximize the channel profits in the supply chain with a wholesaler and one or many retailers. None of these studies takes the interaction and competition between different retailers into account. However, retailer competition influences retailer's pricing of brands significantly [7].

Game theory has been widely used to analyze the marketing and inventory policies in supply chain wide recently. Lariviere and Porteus [8] and Slikker et al. [9] study the news vendor problem by game-theoretical approach. Rhim et al. [10] formulate a supply chain problem as a three-stage non-cooperative game covering location, capacity, and production quantity. However, these research works, each focusing on only one aspect, do not integrate quantity discount and inventory decisions. Besides, none of them takes pricing as marketing decision variable. Little attention has been given to the market structure in which the retailers retain equal as the manufacturers [11]. In most cases, the concept of Nash equilibrium is more general and useful to understand the behavior of the individual supply chain members.

We develop a dynamic game-theoretic framework for this coordination problem. In this game 
framework, the coordination problem is modeled as a dynamic non-cooperative game with complete and perfect information, where the competing retailers formulate a subgame and play the whole game with the manufacturer. This game settles non-cooperative equilibrium (Nash equilibrium) solution such that any chain member cannot improve his profit by acting unilaterally without degrading the performance of the other players.

The remainder of this paper is organized as follows. We give the assumptions and notations underlying our models in Section II. This section also formulates the problem. In Section III, the dynamic non-cooperative game model and solution algorithm are proposed. In Section IV, a numerical example and corresponding sensitivity analysis for some selected parameters have been presented. Finally, this paper concludes in Section V with some suggestions for further work.

\section{Assumptions and notations}

We consider a seller-buyer supply chain, in which the manufacturer purchases raw materials outside to produce substitutable products and delivers them to the different retailers. The substitutability of different products results in the competition between the retailers. These the non-cooperative retailers reach an agreement and as a whole negotiate with the manufacturer on pricing and inventory decisions to maximize their own profits. When the equilibrium is achieved between them, the manufacturer will setup his production and the retailers will then purchase these products and distribute to their customers. We give the following assumptions: Each retailer only sells one type of product. This production-sale inventory model has been implicitly made by [12]; The replenishment time of raw materials is assumed to be integral multipliers of the manufacturer' setup time interval which is also the integer multipliers of all the retailers' replenishment time. This integer multipliers mechanism has also been adopted in many previous works $[13,14]$, which are more general than the inventory policy in other works, such as lot-for-lot procurement policy [15], VMI policy [16]; Different raw materials are used for different products; Shortage are not allowed for the manufacturer, hence the annual production capacity is greater than or equal to the total annual market demand [17]; The manufacturer and the retailers are rational decision makers and have equal market power.

All the input parameters and variables used in our models will be stated as follows. Assume the following relevant parameters for the retailer: $L$ : Total number of retailers; $r_{l}$ : Index of retailer $l$; $R_{r_{i}}$ : Retailer l's annual fixed costs for the facilities and organization to carry this product; $A_{r_{i}}:$ A constant, representing the market scale; $e_{r_{l l}}$ : Coefficient of the product's demand elasticity for retailer $l ; e_{r_{i j}}$ : Coefficient related to the degree that product $j$ could be substitutable by product $l$; $h_{r_{l}}$ : Holding costs per unit of product $l$ for retailer $l ; p_{r_{l}}$ : Retail price charged to the customers by retailer l; $D_{r_{l}}$ : Retailer l's annual demand; The retailer's decision variables are: $\theta_{r_{l}}$ : Retailer l's profit margin; $k_{r_{1}}$ : The integer divisor used to determine the replenishment cycle of retailer $l$; The manufacturer's relevant parameters are: $m$ : Index of the manufacturer; $V_{l}$ : Total number of raw materials used for product $l ; s_{l v_{l}}$ : Index of raw material $v_{l}$ used for product $l, v_{l}=1,2, \ldots, V_{l} ; h_{m p_{l}}$ : Holding costs per unit of product $l ; h_{m s_{V l}}$ : Holding costs per unit of raw material $v_{l}$ used for product $l ; \delta_{s_{l l}}$ : Usage of raw material $v_{l}$ for a unit product $l ; S_{m}$ : Setup cost per production; $O_{m_{l}}$ : Ordering processing cost of raw materials used for product $l$ per order; $P_{l}$ : Annual production capacity product $l$, which is a known constant; $R_{m}$ : Manufacturer's annual fixed costs for the facilities and organization for the production of this product; $p_{m_{l}}$ : Wholesale price charged by the manufacturer to the retailer $l ; c_{m_{l}}$ : Production cost per unit product $l ; c_{s_{l l}}$ : The purchasing cost of raw material $v_{l}$ used for product $l$; The manufacturer's decision variables are: $\theta_{m_{l}}$ : Manufacturer's profit margin 
for product $l ; T$ : Manufacturer's setup time interval; $n_{m_{l}}$ : The integer multiplier used to determine the procurement cycle of raw materials used for product $l$;

\section{Model formulation}

In our game framework, the competing retailers are modeled as a subgame (R-R game) and formulate the whole $\mathrm{M}-\mathrm{R}$ game with the manufacturer. The proposed $\mathrm{M}-\mathrm{R}$ game is, therefore, a dynamic game where the manufacturer's strategies in M-R game affect the retailers' strategies from $\mathrm{R}-\mathrm{R}$ game and, at the same time, the decisions from $\mathrm{R}-\mathrm{R}$ game also affect those decisions in the $\mathrm{M}-\mathrm{R}$ game. Through the dynamic interactions between the $\mathrm{M}-\mathrm{R}$ game and the $\mathrm{R}-\mathrm{R}$ game, individual manufacturer and retailers could determine optimal pricing and inventory decisions to maximize their payoffs.

The demand at each retailer is described by a general demand function of the retail prices. We employ the linear demand function in $[18,19]$ :

$D\left(p_{r_{l}}\right)=A_{r_{l}}-e_{r_{l l}} p_{r_{l}}+\sum_{\substack{j=1,2, \ldots, L \\ j \neq l}} e_{r_{i j}} p_{r_{j}}$, with $A_{r_{l}}>0, e_{r_{l l}}>0, e_{r_{r_{j}}} \geq 0 ; j, l=1,2, \ldots L$.

Because the retailers' 0products are substitutable, we have $e_{r_{i j}} \geq 0$ [20] It can be seen that this demand function is downward sloping and convex functions with respect to $p_{r_{l}}$, since $\frac{\partial D\left(p_{r_{l}}\right)}{\partial p_{r_{l}}}<0, l=1,2, \ldots L$.

The retailer l's objective function is given by the following equation:

$$
\max _{\theta_{\eta}, k_{\eta}} Z_{r_{l}}=\theta_{r_{l}} D_{r_{i}}-\frac{T D_{r_{i}}}{2 k_{r_{l}}} h_{r_{l}}-\frac{O_{r_{l}} k_{r_{i}}}{T}-R_{r_{l}}
$$

Subject to

$$
\begin{aligned}
& k_{r_{l}} \in\{1,2,3, \ldots\}, \\
& \theta_{r_{l}}=p_{r_{l}}-p_{m_{l}}, \\
& D\left(p_{r_{l}}\right)=A_{r_{l}}-e_{r_{l l}} p_{r_{l}}+\sum_{\substack{j=1,2, \ldots, L \\
j \neq l}} e_{r_{r_{j}}} p_{r_{j}}, \\
& \theta_{r_{l}} \geq 0, \\
& 0 \leq D_{r_{l}} \leq P_{l} .
\end{aligned}
$$

Constraint (3) gives the value of the divisor used to determine the retailer l's replenishment cycle time. Constraint (4) indicates the relationship between the prices (the retail price and the wholesale price) and retailer l's profit margin. Constraint (6) ensures that the value of $\theta_{r_{l}}$ is nonnegative. Constraint (7) gives the bounds of the annual demand, which cannot exceed the annual production capacity of the product.

The manufacturer's objective is to determine his strategy $x_{m}$, composed of the profit margins for all the products $\theta_{m_{l}}$, the setup time interval for production $T$ and procurement decision for raw materials $n_{m_{l}}$, to maximize his payoff $Z_{m}$.

The manufacturer faces annual holding costs, setup and ordering costs, and an annual fixed cost. The annual holding cost for the manufacturer is composed of two parts: the cost of holding raw materials used to convert to the products, the cost of holding products. Thus, we can easily derive the manufacturer's payoff function $Z_{m}$ :

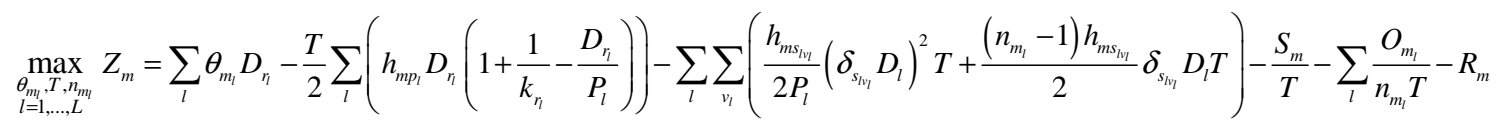

Subject to 


$$
\begin{aligned}
& n_{m_{l}} \in\{1,2,3, \ldots\}, \text { for each } l=1,2, \ldots L \\
& \theta_{m_{l}}=p_{m_{l}}-\sum_{v_{l}} \delta_{s_{V_{l}}} c_{s_{l_{l}}}-c_{m_{l}}, \text { for each } l=1,2, \ldots L \\
& \theta_{m_{l}} \geq 0, \text { for each } l=1,2, \ldots L \\
& T>0 .
\end{aligned}
$$

Constraint (9) gives the value of the multiplier used to determine the manufacturer's procurement cycle time for raw materials need to produce product $l$. Constraint (10) gives the relationship between the price (the wholesale price and the raw material price) and the manufacturer's profit margin. Constraint (11) and (12) ensure that the values of $\theta_{m_{l}}$ and $T$ are nonnegative.

Nash equilibrium is the most popular solution concept in game theory, which is widely used for situations without strictly dominant strategy equilibrium. In this paper, we also apply this Nash equilibrium concept to analyze the strategies of the manufacturer and the retailers in the whole M-R game. We mainly based on analytical theory used by [21] to compute Nash equilibrium. In order to determine the equilibrium of the $\mathrm{M}-\mathrm{R}$ game, we first use analytic method to calculate the best reaction functions of each player and employ algorithm procedure to build the Nash equilibrium.

\section{Test results}

We now illustrate the application of this model by a numerical example. One manufacturer and three retailers are selected. The related input parameters for the base example are based on the suggestions from other researchers $[12,16]$. By applying the above solution procedure in the above section, several interesting findings are summarized as follows:

a) The manufacturer and one retailer could benefit from the increase of market scale parameter / product substitutability parameter or the decrease of demand elasticity, while it is opposite for the other retailers.

b) The increase of one retailer's holding cost will lengthen the manufacturer's setup time interval but shorten the retailer's replenishment cycle time.

c) The increase of the manufacturer's production capacity or decrease of setup cost $S_{m}$ will significantly shorten the manufacturer's setup time interval, while the influence on the chain members' price decisions is minor.

d) When the manufacturer's production cost for one product increases, the retailer's profit will have a most significant decrease, but the other retailers’ profits will increase.

\section{Conclusion}

In this paper, we have considered coordination of pricing and inventory decisions in a seller-buyer supply chain composed of one single manufacturer and multiple competing retailers. The manufacturer and the retailers determine their optimal pricing and replenishment decisions to maximize their individual net profits. This coordination problem is modeled as a non-cooperative dynamic game. We use both analytical and computational methods for the derivation of the optimal decisions of all the chain members. A numerical example has been studied to examine the game model and solution algorithm. Sensitive analysis has been conducted on market parameter and production parameter.

\section{Acknowledgement}

The authors would like to acknowledge the financial support of Macau Foundation (Grant no. 0249) and Macau University of Science and Technology (Grant No. 0237).

\section{References}


[1] Porter, M., Competitive advantage: Creating and sustaining superior performance. New York: The Free Press, 1985.

[2] Chan, L.M.A., Shen, Z.J.M., Simchi-Levi, D., Swann, J.L., Coordination of pricing and inventory decisions: A survey and classification, International Series in Operations Research and Management, Chapter 14, 2004.

[3] Whitin, T.M., “Inventory control and price theory,” Management Science, 2(1), 61-68, 1955.

[4] Kunreuther, H., J.F. Richard, "Optimal pricing and inventory decisions for nonseasonal item," Econometrica, 39(1), 173-175, 1971.

[5] Weng, Z.K, "Channel coordination and quantity discounts," Management Science, 41(9), 1509-1522, 1995.

[6] Boyaci, T., G. Gallego, "Coordinating pricing and inventory replenishment policies for one wholesaler and one or more geographically dispersed retailers," International Journal of Production Economics, 77(2), 95-111, 2002.

[7] Chintagunta, P.K. "Investigating Category Pricing Behavior at a Retail Chain,” Journal of Marketing Research, 39 (2), 141-154, 2002.

[8] Lariviere M.A., E.L. Porteus, "Selling to the newsvendor: an analysis of price-only contracts," Manufacturing Service Operations Management, 3, 293-305, 2001.

[9] Slikker, M., J. Fransoo, M. Wouters "Cooperation between multiple news-vendors with transshipments,” European Journal of Operational Research, 167(2), 370-380, 2005.

[10]Rhim H., Ho, T.H., Karmarkar, U.S., “Competitive location, production, and market selection,” European Journal of Operational Research, 149, 211-228, 2003.

[11]Buzzell, R.D., Quelch, J.A., Salmon, W.J., “The costly bargain of trade promotion,” Harvard Business Review, 1990, 141-149.

[12]Lu, L., “A one-vendor multi-buyer integrated inventory model," European Journal of Operational Research, 81(2), 312-323, 1995.

[13]Hong J., Hayya, S. Kim, "JIT purchasing and setup reduction in an integrated inventory model,” International Journal of Production Research, 30, 255-266, 1992.

[14]Moutaz, K., “Optimizing inventory decisions in a multi-stage multi-customer supply chain,” Transportation Research Part E, 39, 193-208, 2003.

[15] Sarker B.R., G.R. Parija, "An optimal batch size for a production system operating under a fixed-quantity, periodic delivery policy,” Journal of the Operational Research Society, 45, 891-900, 1994.

[16]Woo Y.Y., S.L. Hsu, S. Wu, “An integrated inventory model for a single vendor and multiple buyers with ordering cost reduction,” International Journal of Production Economics, 73, 203-215, 2001.

[17]Esmaeili, M., M. Aryanezhad, P. Zeephongsekul, “A game theory approach in seller-buyer supply chain,” European Journal of Operational Research, 195(2), 442-448, 2009.

[18]McGuire, T.W., R. Staelin, “An industry equilibrium analysis of downstream vertical integration,” Marketing Science, 2, 161-190, 1983.

[19]Jeuland A.P., Shugan S.M., "Channel of distribution profits when channel members form conjectures,” Marketing Science, 7, 202-210, 1988.

[20] Samuelson, P.A., Foundations of economic analysis. Cambridge, Harvard University Press, 1947

[21]Liu, B.D., "Stackelberg-Nash Equilibrium for multilevel programming with multiple followers using genetic algorithms,” Computer Mathematics Application, 36(7), 79-89, 1998. 